\title{
EFEITO DA CONCENTRAÇÃo DE POLPA DE CAJÁ NA PRODUÇÃO DE HIDROMEL POR VIA FERMENTATIVA
}

\author{
Jaqueline dos Santos Bastos ${ }^{1}$; Ernesto Acosta Martínez ${ }^{2}$; Thaíse Souza Amorim ${ }^{3}$ e \\ Sílvia Maria Almeida de Souza ${ }^{4}$ \\ 1. Bolsista PIBIC-AF/CNPq, Graduando em Engenharia de Alimentos, Universidade Estadual de Feira de Santana, e- \\ mail: jaquelinesantos85@hotmail.com \\ 2. Orientador, DTEC, Universidade Estadual de Feira de Santana, e-mail: ernesto.amartinez@ yahoo.com.br \\ 3. Participante, DTEC, Universidade Estadual de Feira de Santana, e-mail: thaaise.s@gmail.com \\ 4. Coordenadora do projeto, DTEC, Universidade Estadual de Feira de Santana, e-mail: ss-almeida@ yahoo..com.br.
}

PALAVRAS-CHAVE: mel; cajá; hidromel.

\section{INTRODUÇÃOO}

No Brasil, a cajazeira é encontrada principalmente nos Estados do Norte e Nordeste, onde suas frutas recebem diferentes denominações sendo conhecidas como: cajá, cajá verdadeiro, cajá-mirim ou taperebá. Essas frutas são comercializadas para consumo como fruta fresca e processamento de polpa como matéria prima no preparo de sucos, picolés, sorvetes, néctares e geleias (Soares et al., 2006). A cajá é rica em vitamina B1, pró-vitamina $\mathrm{A}$, vitamina $\mathrm{C}$ e niacina, minerais como cálcio, fósforo, ferro e potássio. É uma fonte rica de pró- vitamina A (Rodriguez-Amaya \& Kimura, 1989). O hidromel é uma bebida alcoólica (12 a 18\% v/v) fermentada a partir de mel, água e levedura, podendo ser aditivado com ervas, especiarias e frutas durante ou após a fermentação, o que resulta em uma ampla variedade de produtos (Berry, 2007). Este trabalho tem como objetivos estudar o efeito da concentração de polpa de cajá na produção de hidromel por Saccharomyces cerevisiae Montrachet.

\section{MATERIAL E MÉTODOS}

1. Matéria prima: O cajá foi obtido no comercio de Feira de Santana - BA. Realizada a seleção das frutas, higienizadas com solução clorada $(200 \mathrm{ppm})$ por $20 \mathrm{~min}$ e enxaguados com água filtrada. As polpas foram obtidas em despolpadeira semiindustrial e acondicionadas em sacos de polietileno, embalados a vácuo e armazenados sob temperatura de congelamento. Foram realizadas análises físico-químicas tais como pH, acidez, vitamina C e cinzas (Instituto Adolfo Lutz, 2008), proteínas (Galvani \& Gaertner, 2006), densidade e sólidos solúveis por refratômetro. O mel proveniente da Central de Cooperativas dos Apicultores da Bahia (CECOAPI) de Ribeira do Pombal BA foi pasteurizado nas condições segundo Anjos \& Martínez (2015).

2. Processo de fermentação: Foi realizada a propagação da levedura em frascos Erlenmeyer de $250 \mathrm{~mL}(0,3 \mathrm{~g}$ da levedura, 53,55 mL de água esterilizada, 21,45 mL de mel) agitados em shaker $\left(150 \mathrm{rpm}, 30^{\circ} \mathrm{C}, 24 \mathrm{~h}\right)$. A contagem celular em câmara de Neubauer e viabilidade celular pelo uso de azul de metileno. As fermentações foram realizadas em frascos Erlenmeyer de $500 \mathrm{~mL}$ contendo $300 \mathrm{~mL}$ de meio, utilizando concentrações de polpa de cajá de $0,10,20$ e 30\% com relação ao mosto de mel contendo sulfato de amônio $(0,3 \mathrm{~g} / \mathrm{L})$ e cloreto de magnésio $(0,05 \mathrm{~g} / \mathrm{L})$ nas condições de $\mathrm{pH} 4,5,30^{\circ} \mathrm{C}$ durante $288 \mathrm{~h}$ e inoculados com $6,8 \times 10^{6}$ cel $/ \mathrm{mL}$ de $S$. cerevisiae Montrachet. No decorrer do processo fermentativo foram realizadas análises de sólidos solúveis e concentração celular em câmara de Neubauer. As concentrações de sacarose, glicose, frutose, etanol, glicerol e ácido acético na fermentação sem adição de polpa foram determinados em cromatografia liquido de alto desempenho (Waters 410, USA) usando coluna BIORAD AMINEX HPX-87H $(300 \times 7.8)$, detector de índice de refração RID 6A, ácido sulfúrico 0,01N como eluente, taxa de fluxo de 0,6 $\mathrm{mL} / \mathrm{min}$ e 45 ${ }^{\circ} \mathrm{C}$ de temperatura na coluna. 


\section{RESULTADOS E/OU DISCUSSÃO}

$\mathrm{Na}$ Tabela 1 são apresentadas as características físico-químicas da polpa de cajá in natura e as propriedades das polpas de cajá reportadas na literatura.

Tabela 01. Parâmetros físico-química da polpa de cajá in natura e os valores reportados na literatura.

\begin{tabular}{|c|c|c|c|}
\hline Parâmetros Avaliados & $\begin{array}{l}\text { Polpa de Cajá } \\
\text { (in natura) }\end{array}$ & Mattietto et al. (2010) & Sousa et al. (2016) \\
\hline $\mathrm{pH}$ & $2,59 \pm 0,00$ & $2,53 \pm 0,01$ & $2,69 \pm 0,02$ \\
\hline $\begin{array}{l}\text { Sólidos Solúveis Totais } \\
\left({ }^{\circ} \text { Brix }\right)\end{array}$ & $13 \pm 0,05$ & $10,09 \pm 0,00$ & $10,98 \pm 0,36$ \\
\hline $\begin{array}{l}\text { Acidez Total Titulável } \\
(\text { ac.cítrico } / 100 \mathrm{~g} \%)\end{array}$ & $1,63 \pm 0,00$ & $1,86 \pm 0,01$ & $1,68 \pm 0,01$ \\
\hline SS/AT & $7,98 \pm 0,036$ & $5,42 \pm 0,01$ & $6,54 \pm 0,01$ \\
\hline Proteínas (\%) & $0,15 \pm 0,02$ & $0,82 \pm 0,01$ & - \\
\hline Vitamina C (mg/100g\%) & $5,82 \pm 0,04$ & $23,72 \pm 0,08$ & - \\
\hline Cínzas (\%) & $0,82 \pm 0,17$ & $0,58 \pm 0,02$ & $0,37 \pm 0,01$ \\
\hline Densidade $\left(\mathrm{g} / \mathrm{cm}^{3}\right)$ & $0,74 \pm 0,00$ & $0,94 \pm 0,38$ & $1,05 \pm 0,00$ \\
\hline
\end{tabular}

A polpa de cajá teve um pH igual a 2,59 que foi similar a 2,53 e 2,69 reportados por Mattietto et al. (2010) e Sousa et al. (2016), respectivamente. O valor de pH é maior que o mínimo $(2,2)$ estabelecido pela legislação brasileira (Brasil, 2000). A polpa apresentou um maior teor de sólidos solúveis $\left(13,0{ }^{\circ}\right.$ Brix) que o reportado por Mattietto et al. (2010) e Sousa et al. (2016) que foram de 10,09 ${ }^{\circ}$ Brix e 10,98 ${ }^{\circ}$ Brix, respectivamente. A diferença entre esses valores pode estar relacionada com o grau de maturação das frutas, o tipo de solo e nutrientes assim como das condições climáticas durante o cultivo. A fruta de cajá apresenta sabor ácido que nos permite a comprovação de seu sabor pelo valor de acidez de $1,63 \%(\mathrm{~g} / 100 \mathrm{~g})$ em ácido cítrico, valor este inferior aos reportados por Mattietto et al. (2010) e Sousa et al. (2016), 1,86\% e 1,68\%, respectivamente. Estes valores de acidez estão acima dos valores mínimos de acidez $(0,9)$ estabelecidos pela legislação brasileira (Brasil, 2000). Este parâmetro é o responsável pelo sabor ácido ou azedo dos frutos sendo importante na análise do estado de conservação de um produto alimentício. A relação SS/AT de polpa de frutas é uma das melhores formas para avaliar o seu sabor que ocorre geralmente como resultado do balanço de açúcares e ácidos sendo mais representativo que a medição dos dois parâmetros isoladamente (Batista et al., 2013). As polpas utilizadas neste trabalho possuem uma maior relação SS/AT $(7,89)$ que as outras polpas reportadas na literatura. Os teores de proteínas totais apresentam valores bem abaixo da literatura, valor este de 0,15\% de proteína presente na polpa de cajá ao comparado com Mattietto et al. (2010) que reporta um teor de $0,82 \%$ e quando comparado com a TACO (2011) que apresenta $0,6 \%$ de proteína presente na polpa. A polpa de cajá apresentou um teor médio de ácido ascórbico de 5,82 mg em $100 \mathrm{~g}$ de polpa, muito inferior ao reportado por Mattietto et al. (2010) e maior quando comparado com a TACO (2011) que apresenta apenas traços de vitamina $\mathrm{C}$ em 100 gramas de polpa. Os teores de cinzas resultaram um valor médio de $0,82 \%$, valor este acima de $0,58 \%$ e $0,37 \%$ reportados por Mattietto et al. (2010) e Sousa et al. (2016), respectivamente. As diferenças podem ser atribuídas ao tipo e composição dos solos. A densidade da polpa de cajá encontrada foi de $0,74 \mathrm{~g} / \mathrm{cm}^{3}$ inferior a $0,94 \mathrm{~g} / \mathrm{cm}^{3}$ e $1,05 \mathrm{~g} / \mathrm{cm}^{3}$ reportados por Mattietto et al. (2010) e Sousa et al. (2016), respectivamente.

Na Figura 1 A e B apresentam-se os perfiles de concentração de açúcares (sacarose, glicose e frutose), etanol, glicerol, ácido acético e células durante a fermentação do mosto de mel e água ( $30^{\circ}$ Brix) e de sólidos solúveis, etanol e células com 10, 20 e 30\% de polpa de cajá pela levedura $S$. cerevisiae Montrachet, respectivamente. O mosto tinha 
uma composição inicial de açúcares de 53,1 g/L de sacarose, 112,2 /L de glicose e 127,9 $\mathrm{g} / \mathrm{L}$ de frutose.
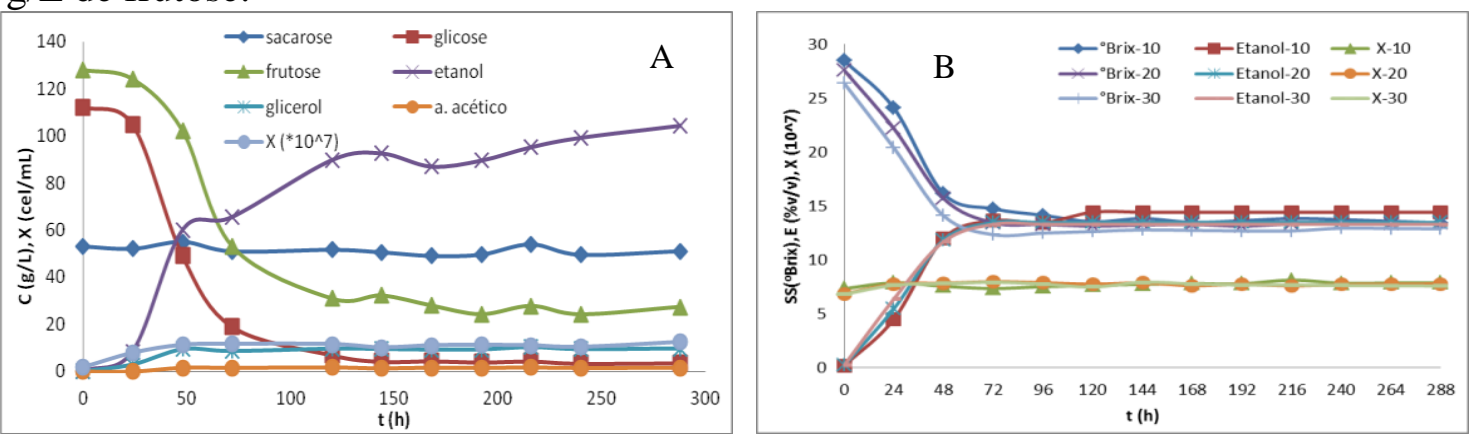

Figura 1: A. Concentrações de açúcares (sacarose, glicose e frutose), etanol, glicerol, ácido acético e concentração celular durante a fermentação do mosto de mel e água (30 ${ }^{\circ}$ Brix) e B: Perfiles de sólidos solúveis ( ${ }^{\circ}$ Brix), concentração de etanol e células durante a fermentação do mosto de mel e água (30 ${ }^{\circ}$ Brix) com 10, 20 e 30\% de polpa de cajá pela levedura S. cerevisiae Montrachet.

A concentração de sacarose se manteve praticamente constante ao longo do processo fermentativo e os fermentados obtidos com 10, 20 e 30\% de polpa contem sólidos solúveis finais iguais a 13,4; 13,4 e 12,9 que podem estar relacionados com a sacarose no meio a qual por ser um dissacarídeo não pode ser metabolizada pelo microrganismo (Figura 1A, B). Após $48 \mathrm{~h}$ de fermentação foram constatados consumos acentuados de $56,25 \%$ de glicose e de $20,13 \%$ de frutose pela $S$. cerevisiae os quais foram usados na produção de $60,0 \mathrm{~g} / \mathrm{L}$ de etanol $(7,55 \% \mathrm{v} / \mathrm{v}), 9,4 \mathrm{~g} / \mathrm{L}$ de glicerol e 1,5 g/L de ácido acético assim como para o crescimento celular $\left(6,2 \times 10^{7} \mathrm{cel} / \mathrm{mL}\right)$. Consumos de $83,1 \%$ e 58,52\% de glicose e frutose, respectivamente e a produção de $65,5 \mathrm{~g} / \mathrm{L}$ de etanol e 10 x $10^{7} \mathrm{cel} / \mathrm{mL}$ foram verificados após $72 \mathrm{~h}$ de fermentação (Figura 1A). Ao final do processo fermentativo foi produzido um hidromel contendo $3,6 \mathrm{~g} / \mathrm{L}$ de glicose $(96,8 \%$ de consumo), 27,4 g/L de frutose (78,6\% de consumo), 104,3 g/L de etanol (14,7\%v/v) e concentração celular de $12,4 \times 10^{7} \mathrm{cel} / \mathrm{mL}$. As concentrações de glicerol e ácido acético se mantiveram praticamente constantes no hidromel a partir das $48 \mathrm{~h}$ de fermentação. Nas primeiras $48 \mathrm{~h}$ de fermentação, independentemente da concentração de polpa utilizada no mosto, observa-se uma diminuição acentuada do teor de sólidos solúveis ( ${ }^{\circ}$ Brix) e um aumento na produção de etanol pela levedura (Figura 1B). Após $48 \mathrm{~h}$ de fermentação foram constatados consumos aproximados de 43,3\%, 43,1\% e 46,6\% de açúcares ( ${ }^{\circ}$ Brix) pela $S$. cerevisiae os quais foram usados na produção de $94,6 \mathrm{~g} / \mathrm{L}$ $(12 \% \mathrm{v} / \mathrm{v}), 93,5 \mathrm{~g} / \mathrm{L}(11,9 \% \mathrm{v} / \mathrm{v})$ e $92,4 \mathrm{~g} / \mathrm{L}(11,7 \% \mathrm{v} / \mathrm{v})$ de etanol, assim como para o crescimento celular $\left(3,7 \times 10^{7} \mathrm{cel} / \mathrm{mL}, 7,1 \times 10^{7} \mathrm{cel} / \mathrm{mL}\right.$ e $\left.6,4 \times 10^{7} \mathrm{cel} / \mathrm{mL}\right)$ na concentração com 10, 20 e 30\% de polpa de cajá, respectivamente. Após 72 h de fermentação o teor de sólidos solúveis e a concentração de etanol se mantiveram praticamente constantes e pode ser verificado que o número de célula se manteve praticamente constante no processo fermentativo sem polpa e nas três concentrações de polpa de cajá utilizadas (Figura 1A, B). Similares resultados em relação aos valores de sólidos solúveis e etanol constantes foram relatados por Ilha et al. (2008). Consumos de açúcares de $48,2 \%, 51,3 \%$ e $54,1 \%$, a produção de etanol de $107,66 \mathrm{~g} / \mathrm{L}, 106,37 \mathrm{~g} / \mathrm{L}$ e $105,06 \mathrm{~g} / \mathrm{L}$ e de células de $2,3 \times 10^{7} \mathrm{cel} / \mathrm{mL}, 1,0 \times 10^{8} \mathrm{cel} / \mathrm{mL}$ e $8,8 \times 10^{7} \mathrm{cel} / \mathrm{mL}$ foram verificados após $72 \mathrm{~h}$ de fermentação nos meios de fermentação contendo 10, 20 e $30 \%$ de polpa de cajá, respectivamente. Ao final do processo fermentativo $(288 \mathrm{~h})$ foram produzidos hidroméis contendo 103,93 g/L de etanol (14,44\%v/v), 106,36 g/L de etanol $(13,48 \% \mathrm{v} / \mathrm{v})$ e $105,1 \mathrm{~g} / \mathrm{L}$ de etanol $(13,31 \% \mathrm{v} / \mathrm{v})$ e concentração celular de $7,8 \times 10^{7}$ $\mathrm{cel} / \mathrm{mL}, 6,1 \times 10^{7} \mathrm{cel} / \mathrm{mL}$ e $3,9 \times 10^{7} \mathrm{cel} / \mathrm{mL}$ com o uso de 10,20 e $30 \%$ de polpa de cajá no mosto, respectivamente. A viabilidade celular foi maior que 97,90 e $92 \%$ ao longo do processo fermentativo nos meios contendo 10, 20 e $30 \%$ de polpa de cajá, 
respectivamente. $\mathrm{O}$ maior valor $(1,9 \mathrm{~g} / \mathrm{L} . \mathrm{h})$ de produtividade em etanol foi obtido durante a fermentação do hidromel contendo polpa após $48 \mathrm{~h}$ de fermentação, valor $36,8 \%$ superior ao obtido no meio contendo mel e água. Maiores valores de fator de conversão de substrato em produto $(0,42 \mathrm{~g} / \mathrm{g})$ e de eficiência $(82,2 \%)$ foram obtidos sem a adição de polpa ao mosto. $O$ fator de conversão foi de $0,40 \mathrm{~g} / \mathrm{g}$ nas fermentações com polpa de cajá durante o tempo de fermentação. Ilha et al. (2008) a partir da fermentação do mel silvestre diluído em água $\left(21^{\circ}\right.$ Brix $)$ nas condições de temperatura ambiente e $\mathrm{pH}$ 4,5 durante 84 h de fermentação obteve um hidromel com teor alcoólico de 8,02\% (v/v), rendimento de fermentação de $41,53 \%$ e eficiência de fermentação de $81,27 \%$.

\section{CONSIDERAÇÕES FINAIS}

A polpa de cajá possui propriedades físico-químicas de acordo com a legislação brasileira o que permite seu uso como matéria-prima na produção de outros alimentos. É possível produzir hidromel com polpa de cajá a partir das $48 \mathrm{~h}$ de fermentação. A produtividade volumétrica em etanol sempre foi maior no meio contendo polpa mesmo com o aumento do tempo de fermentação.

\section{REFERÊNCIAS}

ANJOS, M. B.; MARTINEZ, E. C. 2015. Efeito do tratamento térmico nas propriedades físicoquímicas e microbiológicas do mosto do mel. Trabalho de Iniciação Científica - PROBIC. Feira de Santana.

BATISTA, Â. G.; OLIVEIRA, B. D'.; OLIVEIRA, M. A.; GUEDES, T. J.; SILVA, D. F.; PINTO, N. A.; VILLELA D. 2013. Parâmetros de qualidade de polpas de frutas congeladas: uma abordagem para produção do agronegócio familiar no Alto Vale do Jequitinhonha. Tecnol. \& Ciên. Agropec, 7(4):49-54, dez.

BERRY, B. 2007. The global mead market: opportunities for Canadian mead exporters. Ottawa,

Ontário; Agriculture and Agri-Food Canada. Disponível em: <http://atssea.agr.gc.ca/canada/4347_e.htm>. Acesso em: 21 de Março de 2016.

BRASIL. 2000. Ministério da Agricultura, Pecuária e Abastecimento. Instrução Normativa no 01, de 07 de janeiro de 2000. Aprova o Regulamento técnico geral para fixação dos padrões de identidade e qualidade para polpa de fruta. Disponível em: <http://extranet.agricultura.gov.br>. Acesso em: 09 mar. 2011

GALVANI, F.; GAERTNER, E. 2006. Adequação da Metodologia Kjeldahl para determinação de Nitrogênio Total e Proteína Bruta, Corumbá-MS., Maio. Disponível em: < http://www.cpap.embrapa.br/publicacoes/online/CT63.pdf >. Acesso em: 10 jun. 2015.

ILHA, E. C.; BERTOLDI, F.C; REIS, V. D. A.; SANT'ANNA, E. 2008. Rendimento $e$ Eficiência da Fermentação Alcoólica na Produção de Hidromel. Boletim de Pesquisa e Desenvolvimento EMBRAPA (Empresa Brasileira de Pesquisa Agropecuária). ISSN 19817215. Dezembro.

INSTITUTO ADOLFO LUTZ. 2008. Métodos físico-químicos para análise de alimentos. 4. ed. São Paulo: Instituto Adolfo Lutz, 2008.

MATTIETTO, R. A.; LOPES, A. S.; MENEZES, H. C. 2010. Caracterização física e físicoquímica dos frutos da cajazeira (Spondias mombin L.) e de suas polpas obtidas por dois tipos de extrator. Braz. J. Food Technol., Campinas, 13(3):156-164, jul./set.

RODRIGUEZ-AMAYA, D. B.; KIMURA, M. 1989. Caratenóides e valor de vitamina A em cajá ( Spondias lútea). Ciência e Tecnologia de Alimentos, 9(2):148-162.

SOARES, E .B.; GOMES, R. L. F.; CARNEIRO, J. G. M.; NASCIMENTO, F. N.; SILVA, I. C. V.; COSTA, J. C. L. 2006. Caracterização físico e química de frutos de cajazeira. Revista Brasileira de Fruticultura. Jaboticabal-SP, 28(3): 518-519.

SOUSA, F. C.; SILVA, L. M. M.; CASTRO, D. S.; MOREIRA, I. S.; ROCHA, A. P. T. 2016. Caracterização do cajá in natura, formulado e liofilizado. In: CONGRESSO TÉCNICO CIENTÍFICO DA ENGENHARIA E DA AGRONOMIA. Foz de Iguaçu, PR.

TACO 2011. Tabela brasileira de composição de alimentos. 4. ed., Campinas, SP:NEPAUNICAMP. 161p. 